\title{
Monitoreo de la actividad de influenza en Santa Fe, Argentina, 2005-2010
}

\author{
Gabriela Kusznierz, Raquel Cociglio, Juan C. Beltramino, Judith Pierini, José De Jorge, \\ Alejandra Gómez, Gerardo Pigliacampo, Elsa Carrasco, Adriana Cesoni y Susana Imaz
}

\section{Monitoring of activity of influenza in Santa Fe, Argentina, 2005-2010}

Background. Influenza viruses have a relevant public health impact. Objective. To describe the activity of influenza and assess the morbidity and mortality impact during 2005 to 2010 in Santa Fe, Argentina. Methods. Epidemiological and virological indicators were calculated based on sentinel surveillance. Mortality data from patients over and under the age of 65 were analyzed using the integrated autoregressive moving average model and an excess of mortality attributable to influenza was determined. Results. The viral circulation effect on morbidity was measured through the evolution in the proportion of influenza-like illness (ILI) patients. Peak incidence was observed between weeks 23 and 33. An excess of deaths was identified in 2007 among patients over 65 and among those under 65 in 2009, which was related with influenza A(H3N2) and A(H1N1)pandemic virus circulation respectively, associated with a higher proportion of virus recovery and a higher ILI percentage. Conclusions. The sentinel surveillance of influenza is a simple and efficient methodology that identifies influenza trends. Our study showed that the virus has caused a rise of mortality in patients $>65$ in epidemic periods associated with the H3N2 subtype and in patients $<65$ in the pandemic period with the circulation of $\mathrm{A}(\mathrm{H} 1 \mathrm{~N} 1)$ pandemic virus.

Key words: influenza, mortality, sentinel surveillance, Argentina.

Palabras clave: influenza, unidad centinela, mortalidad, Argentina.

\section{Introducción}

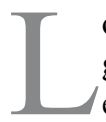

os virus influenza son agentes patógenos de gran importancia para la salud pública, ya que especialmente el virus influenza A está asociado a un incremento en las consultas médicas, en las tasas de hospitalización y de mortalidad ${ }^{1,2}$. Como el potencial epidémico de los virus influenza depende principalmente de las variaciones antigénicas, la vigilancia virológica es fundamental y la OMS en 1947 implementó la vigilancia viral como objetivo principal para identificar los virus circulantes que permitan la formulación anual de la vacuna. Muchos países ${ }^{3-6}$ han establecido programas de vigilancia virológica y clínica para monitorear la actividad de la enfermedad tipo influenza (ETI), basados en variadas estrategias de vigilancia, destacándose la vigilancia centinela en la práctica médica general.

La vigilancia epidemiológica de la influenza (o gripe) mediante Unidad Centinela ${ }^{7}$ tiene como objetivos conocer la contribución de las ETI con referencia al total de consultas realizadas por los médicos centinelas; determinar la frecuencia, estacionalidad y distribución geográfica del virus influenza y otros virus respiratorios; determinar la concordancia entre la vacuna y las cepas que están en circulación; detectar oportunamente la aparición de nuevos subtipos y aportar cepas virales para la formulación de la vacuna de influenza.
A fin de evaluar la magnitud de las epidemias de influenza, en distintos países se han analizado los datos de mortalidad utilizando diferentes modelos estadísticos, asumiendo que el número de muertes que excede la línea de base esperada durante una epidemia de influenza está relacionada a influenza ${ }^{8-10}$. Choi y Tracker ${ }^{11,12}$ utilizaron el método ARIMA (método auto-regresivo integrado de promedio móviles) para construir un modelo de mortalidad por neumonía e influenza.

El objetivo de este trabajo fue describir la actividad de la influenza y evaluar su impacto en la morbilidad y mortalidad durante el período 2005 a 2010 en la población de Santa Fe, Argentina.

\section{Material y Método}

Diseño del estudio: Se trata de un estudio descriptivo de tipo retrospectivo.

Lugar del estudio: El estudio se concentró en el período 2005 a 2010 en el Departamento La Capital de la Provincia de Santa Fe, Argentina. La población estimada durante ese período varió desde 524.174 a 547.496 habitantes; en mayores de 65 años osciló entre 53.711 y 56.101 habitantes y en menores de 65 años, de 470.463 a 491.395 habitantes, según el Instituto Provincial de Estadística y Censo (IPEC) de la Provincia de Santa Fe.
Provincia de Santa Fe, Argentina.

Instituto Nacional de Enfermedades Respiratorias "Dr. Emilio Coni" (GK, AG, SI).

Hospital de Niños "Dr. O. Alassia" (RC, JCB, JDJ).

Hospital "J. B. Iturraspe", Servicio de Pediatría. (JP).

Centro de Salud Gutiérrez Este, Hospital "J. B Iturraspe" (GP). Centro de Salud Barranquita Oeste, Hospital "J. B Iturraspe" (EC). Centro de Salud Evita, Hospital "J. M Cullen" (AC).

Los autores han declarado que no existen conflictos de intereses. No existen fuentes de financiamiento.

Recibido: 12 de marzo de 2013 Aceptado: 18 de enero de 2014

\section{Correspondencia a:} Gabriela Kusznierz kusznierz@yahoo.com 
El estudio se basó en el análisis de los datos proporcionados por el sistema de unidad centinela de influenza, el sistema de vigilancia epidemiológica de enfermedades comunicables y la mortalidad por neumonía e influenza.

Unidad Centinela de Influenza: En Santa Fe, la Unidad Centinela de Influenza es coordinada por el Instituto Nacional de Enfermedades Respiratorias "Dr. Emilio Coni” (INER). La estructura organizativa está conformada por tres componentes: clínico, de laboratorio y epidemiológico.

Definición de caso de ETI: Paciente de cualquier edad, con fiebre superior a $38^{\circ} \mathrm{C}$, acompañado de tos o faringodinia.

Población objetivo: Pacientes de todas las edades, asistidos de forma ambulatoria por el médico centinela en el establecimiento de salud seleccionado como integrante de la unidad Centinela de ETI.

Tipo de muestreo: Se utilizó el muestreo sistemático por cuotas.

Tamaño y metodología de selección de la muestra: Se realizó la toma de muestra de al menos tres pacientes por semana epidemiológica, de cualquier edad, que cumpliera con la definición de caso de ETI, con menos de $72 \mathrm{~h}$ de iniciado los primeros síntomas, atendidos por cada médico centinela durante todo el año, iniciando con el primer caso atendido cada semana y continuando hasta que se alcanzó el tamaño de la cuota fijada.

\section{Vigilancia clínica}

El componente clínico estuvo conformado por 19 médicos centinelas voluntarios, de los cuales, cuatro son pediatras y 15 son médicos clínicos que reportan el número semanal de pacientes asistidos con ETI que cumplen con la definición de caso y el número total de consultas. Los médicos centinelas están distribuidos en las salas de guardia de tres hospitales, 11 centros de atención primaria y dos consultorios privados. Los médicos centinelas realizaron la toma de muestras de hisopados nasales y faríngeos a pacientes que cumplieron con la definición de caso. Las muestras fueron remitidas al laboratorio del INER acompañada de una planilla clínico-epidemiológica.

\section{Vigilancia virológica}

El componente laboratorio localizado en el INER tiene la función de realizar la identificación de los virus respiratorios: influenza $\mathrm{A}$ y $\mathrm{B}$, virus respiratorio sincicial, adenovirus y parainfluenza mediante la técnica de inmunofluorescencia. A partir del año 2010 se incorporó la técnica de reacción de polimerasa en cadena en tiempo real (RPC-TR) para la detección de influenza A subtipo H1, H3 e influenza B. Todas las muestras positivas para el virus influenza de cada temporada se aíslan en líneas celulares y luego los aislamientos son enviados al Laboratorio de Referencia Nacional de Influenza del Instituto Nacional de Enfermedades Infecciosas "Carlos Malbrán", en el cual una selección del total de estos virus son sub-tipificados y caracterizados antigénicamente y genéticamente. Parte de los resultados son confirmados y completados por el Centro para el Control y Prevención de Enfermedades (CDC) de Atlanta, Georgia, Estados Unidos de América (E.U.A.).

\section{Vigilancia epidemiológica}

Procedimiento de reporte: El componente epidemiológico integrado por el servicio de atención primaria y el servicio de epidemiología de los hospitales participantes son los encargados de recopilar la información de las consultas de ETI de cada médico centinela y remitirla al INER. La información epidemiológica, clínica y virológica se inserta semanalmente en una plataforma informática vía web del Sistema Nacional de Vigilancia en Salud (SNVS), para proporcionar información puntual sobre la actividad de influenza a nivel provincial y nacional.

Indicadores epidemiológicos: A partir de la información proporcionada por el sistema se han calculado:

- Indicadores epidemiológicos: porcentaje semanal de casos de ETI (se usó como denominador las consultas totales semanales) por temporada.

- Indicadores virológicos: distribución anual de virus por tipo/subtipo, número de virus influenza semanal, porcentaje de positividad en el período epidémico y duración del período epidémico.

Notificación de síndrome tipo influenza. De acuerdo con las normas del Sistema Nacional de Vigilancia Epidemiológica (SINAVE) en Santa Fe, todos los servicios de salud pública notifican semanalmente a través de la planilla $\mathrm{C} 2$ y de forma obligatoria los casos de ETI atendidos, tanto sean hospitalizados como ambulatorios.

\section{Mortalidad}

La recopilación de los datos de la mortalidad por neumonía e influenza se realizó en todos los grupos de edad registrada desde el año 2005 a 2010 del Departamento La Capital, información que se obtuvo de la Dirección General de Estadísticas del Ministerio de Salud y Medio Ambiente de la Provincia de Santa Fe. La Dirección de Estadística cuenta con un sistema informatizado, donde la codificación de la causa de muerte está basada en "la causa básica de la muerte", y no tiene en cuenta la causa respiratoria que figura en otro orden. Por esta razón, se identificaron manualmente en forma mensual aquellos 
certificados de defunción en los cuales se mencionaba la neumonía o influenza como causa de muerte, sin importar el orden en el certificado. Una muerte por neumonía e influenza se definió como una muerte en la cual figurara uno de los siguientes códigos según la Clasificación Internacional de Enfermedades (CIE): J10-18.

Exceso de mortalidad y modelo de la serie. La mortalidad mensual se estudió considerando dos grupos de edad, personas menores y mayores de 65 años mediante el análisis de series temporales basado en el modelo de Box-Jenkins, de manera de estimar el exceso de muertes atribuibles a neumonía e influenza en ausencia de epidemia (muertes esperadas). Para calcular el número de muertes esperadas, se utilizó el programa SSS13,14 (Statistical Sofware for Public Health Surveillance 1) del CDC. El número de "muertes esperadas", es decir el número de muertes "base" que se esperarían en ausencia de una epidemia de influenza, se calculó prospectivamente, empleando el número de muertes registradas durante meses anteriores (a partir de 2006), previo reemplazo de los datos correspondientes a períodos epidémicos, por aquellos calculados por el modelo para los períodos no epidémicos. Este modelo permite identificar períodos en los cuales el número de muertes excede el umbral epidémico (definido como todo lo que sobrepasa el límite superior del intervalo de confianza del 95\% de las muertes esperadas). La estimación del exceso de muertes en cada estación se realizó basándose en la diferencia entre el número de muertes observadas y el número de muertes esperadas, en los meses en que el número de muertes observadas excedió el umbral epidémico; y esto coincide con un aumento en la proporción de ETI por encima del umbral basal y la detección de virus influenza.

Para comparar la proporción de aislamientos obtenidos (durante el período epidémico) y el porcentaje de ETI (máximo indicador) en los períodos con y sin exceso de muertes, se utilizó la prueba $\chi^{2}$ de Pearson. Se utilizó también la propiedad de partición $\chi^{2}$ para comprender la estructura de datos y analizar qué categorías llevan al rechazo de la hipótesis de igualdad de proporciones y un análisis de residuos ajustados mediante distribución normal para analizar las diferencias entre valores observados y ajustados.

\section{Definiciones}

Se ha considerado período epidémico de cada temporada de gripe al correspondiente a las semanas epidemiológicas en las que la proporción de ETI sobrepasa el umbral basal de actividad acompañado de la detección de virus influenza. El umbral basal de la actividad gripal semanal se ha establecido como la media de la proporción de ETI de todo el período 2005-2010, más dos desviaciones estándares de las semanas en las que no se detecta virus influenza.
Consideramos un tipo/subtipo A(H3N2), A(H1N1) o B predominante de la estación de influenza utilizando el criterio de Fleming y cols. ${ }^{15,16}$, según el cual en cada estación se considera tipo/subtipo predominante de virus a aquel que se identifica en más de $50 \%$ del total de los aislados. Cuando un segundo tipo/subtipo se identifica en $25 \%$ o más de los aislados de la estación, éste es también considerado predominante aun cuando no alcanza a representar más de $50 \%$ de los aislados.

\section{Resultados}

\section{Unidad Centinela de Influenza}

Vigilancia epidemiológica. Entre los años 2005 y 2010 , el aumento de la actividad de influenza se inició en la semana epidemiológica $21^{\mathrm{a}}$ y no finalizó hasta la semana $35^{\mathrm{a}}$. En los años 2005, 2006 y 2009 el máximo indicador se alcanzó en la semana 26 (julio) y en 2008 en la semana $27^{\mathrm{a}}$, coincidiendo con la identificación de virus influenza A y B (Tabla 1). En el año 2007, en cambio, se alcanzó el máximo indicador en la semana 23 ${ }^{\mathrm{a}}$ (junio). Durante 2010 la proporción de ETI se incrementó más tardíamente, a partir de la semana $32^{\mathrm{a}}$ y el pico en la semana $33^{\mathrm{a}}$. A partir de la semana $43^{\text {a }}$ del mismo año, se detectó la circulación de virus influenza A (H3N2), sin evidenciarse un aumento en la proporción de ETI (Figuras 1 y 2). El umbral basal durante el período analizado se estableció en 5,52\% y fue superado durante una mediana de 5,5 semanas (rango: 3-10 semanas) (Figura 1).

Durante el período estudiado, los médicos centinelas reportaron 19.156 casos de ETI; en el año 2005 se registraron 2.171 casos de ETI; en 2006: 3.391; en 2007: 3.137; en 2008: 2.177; en 2009: 5.224 y en el 2010: 3.056 casos.

El total de notificaciones por ETI para el Departamento La Capital durante 2005-2010 fue 67.038 según los datos provistos por el Departamento de Epidemiología (Dirección de Promoción y Protección de la Salud) del Ministerio de Salud y Medio Ambiente de la Provincia de Santa Fe. La comparación temporal de los indicadores "Porcentaje de ETIs entre los pacientes vistos en los consultorios de los médicos centinelas" con el "número de notificaciones de ETIs a través de la planilla C2", evidenció que existe coincidencia temporal en los picos de los gráficos (Figura 3 ).

Circulación virológica. Durante las siete estaciones estudiadas (2005-2010), hubo seis períodos de circulación de influenza A y un período de circulación de influenza B. Durante 2005 co-circularon influenza A y B. Durante el 2010 se registró una primera onda de circulación de virus influenza A y cuatro semanas más tarde, una segunda onda de circulación de influenza B (Tabla 1).

Durante este período, se recibieron 1.303 hisopados 
Tabla 1. Proporción máxima de enfermedad tipo influenza; cepa viral detectada; inicio, pico y final de período epidémico;

duración del período epidémico; proporción de positividad en período epidémico; duración de la circulación viral, exceso de mortalidad por neumonía e influenza en $>$ y $<$ de 65 años, Santa Fe, Argentina 2005-2010

\begin{tabular}{|c|c|c|c|c|c|c|c|c|c|c|}
\hline \multirow[t]{2}{*}{ Año } & \multirow[t]{2}{*}{ Cepa viral } & \multirow{2}{*}{$\begin{array}{c}\text { Positividad } \\
\text { período } \\
\text { epidémico } \\
\%\end{array}$} & \multirow{2}{*}{$\begin{array}{l}\text { Duración de la } \\
\text { circulación } \\
\text { viral } \\
\text { (semanas) }\end{array}$} & \multicolumn{3}{|c|}{$\begin{array}{l}\text { Período epidémico } \\
\text { (semana) }\end{array}$} & \multirow{2}{*}{$\begin{array}{l}\text { Duración } \\
\text { período } \\
\text { epidémico } \\
\text { (semanas) }\end{array}$} & \multirow{2}{*}{$\begin{array}{c}\text { Máximo } \\
\text { indicador } \\
\text { de ETI } \\
\%\end{array}$} & \multirow{2}{*}{$\begin{array}{c}\text { Exceso de mortalidad } \\
\text { por neumonía e } \\
\text { influenza en }>65 \\
\text { (intervalo) } \\
n\end{array}$} & \multirow{2}{*}{$\begin{array}{c}\text { Exceso de mortalidad } \\
\text { por neumonía e } \\
\text { influenza en }<65 \\
\text { (intervalo) } \\
n\end{array}$} \\
\hline & & & & Inicio & Pico & Final & & & & \\
\hline 2005 & $\begin{array}{l}\text { A/California/7/2004(H3N2)a } \\
\text { B/Hong Kong/330/01 }\end{array}$ & 4,2 & $22-34$ & 23 & 26 & 32 & 10 & 13,8 & NA & NA \\
\hline 2006 & A/New Caledonia/20/99 (H1N1) & 12,5 & $21-27$ & 24 & 26 & 28 & 5 & 13,3 & 0 & 0 \\
\hline 2007 & $\begin{array}{l}\text { A/Brisbane/10/07 (H3N2) } \\
\text { A/Wisconsin/67/05(H3N2) }\end{array}$ & 20,7 & $21-26$ & 21 & 23 & 26 & 6 & 14,4 & $46(7-66,2)$ & 0 \\
\hline 2008 & A/Brisbane/59/07 (H1N1) & 6,5 & $25-27$ & 25 & 27 & 27 & 3 & 12,8 & 0 & 0 \\
\hline 2009 & A/California/7/07(H1N1) & 64,7 & $22-42$ & 22 & 26 & 28 & 9 & 34,4 & 0 & $33(13-40,3)$ \\
\hline 2010 & $\begin{array}{l}\text { B/Brisbane/60/2008 } \\
\text { A/Perth/16/2009 (H3N2) }\end{array}$ & $\begin{array}{l}25,6 \\
25\end{array}$ & $\begin{array}{l}31-36 \\
43-52\end{array}$ & $\begin{array}{r}32 \\
0\end{array}$ & $\begin{array}{r}33 \\
0\end{array}$ & $\begin{array}{r}35 \\
0\end{array}$ & 4 & 11 & 0 & 0 \\
\hline
\end{tabular}

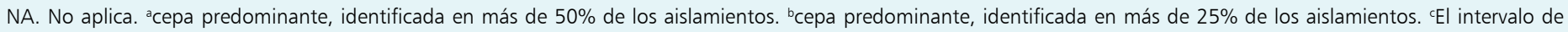
confianza se calculó teniendo en cuenta los límites de confianza superior e inferior del número de muertes esperadas.

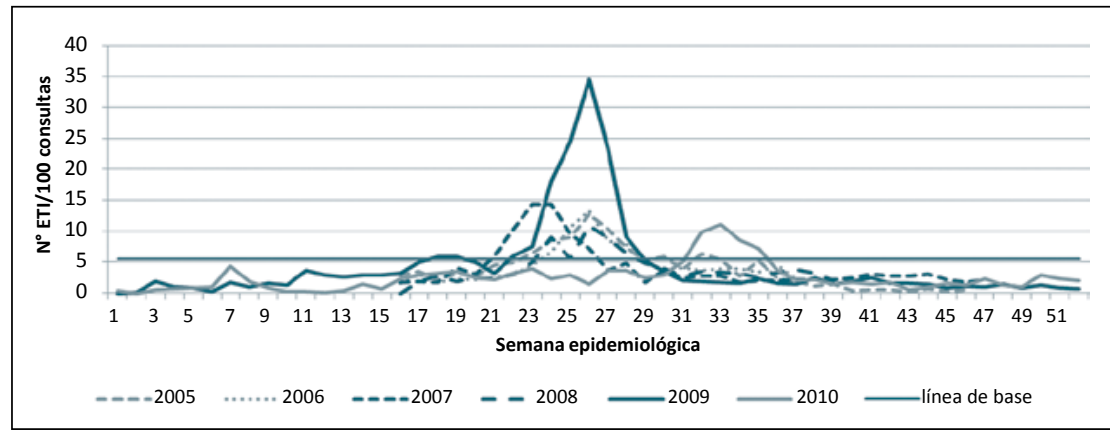

Figura 1. Proporción semanal de ETI cada 100 consultas durante el período 2005-2010. Unidad Centinela de Influenza, Santa Fe, Argentina.

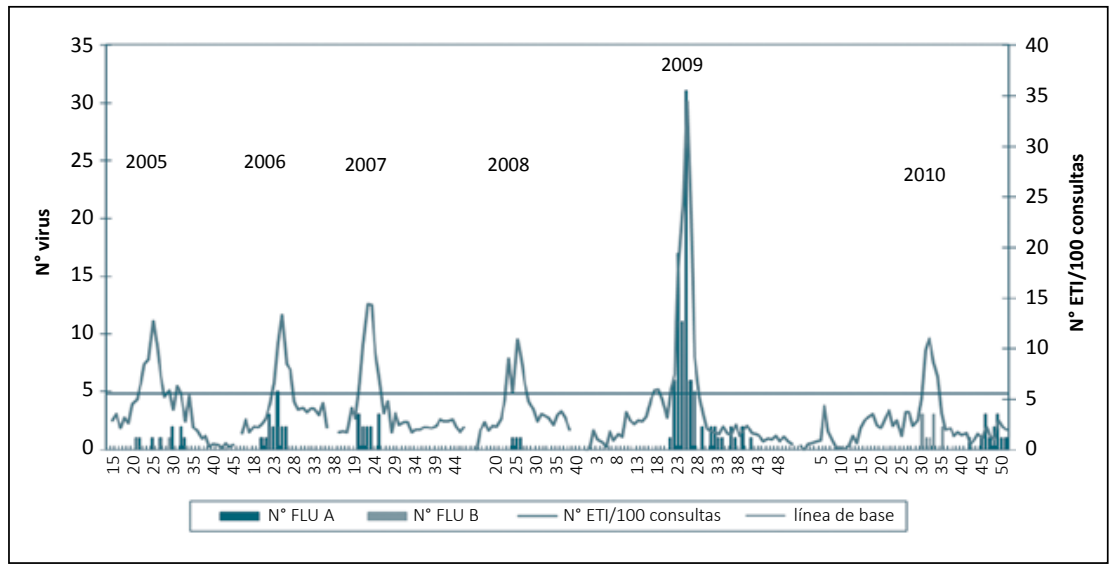

Figura 2. Proporción de ETI cada 100 consultas y distribución semanal de virus influenza, Unidad Centinela de Influenza, Santa Fe, Argentina, 2005-2010. nasales y faríngeos de pacientes con ETI, en el 2005: 332 muestras, en el 2006: 232, en el 2007: 102, en el 2008: 186, en el 2009: 223 y en el año 2010: 228. El porcentaje de positividad en el período epidémico varió entre 4,2 y 64,7\% (Tabla 1).

Mortalidad. En Santa Fe, durante el período 2005 a 2010 se reportó un total de 3.119 muertes por neumonía e influenza, 642 (20,6\%) en menores de 65 años y 2.477 $(79,4 \%)$ en mayores de 65 años. Entre los mayores de 65 años, en 2005 se reportaron 249 muertes, en el 2006: 391, en el 2007: 553, en el 2008: 430, en el 2009: 410 y en el año 2010: 444. Entre los menores de 65 años en 2005 se registraron 68 muertes, en el 2006: 91, en el 2007: 124, en el 2008: 94, en el 2009: 138 y en el año 2010: 127 muertes. El exceso de mortalidad atribuible a neumonía e influenza, donde la mortalidad excede el límite superior del intervalo de confianza de $95 \%$, se muestra en las Figuras 4 y 5 . En los mayores de 65 años, el exceso se registró en el año 2007 durante el mes de junio, el cual se caracterizó por la circulación de influenza A (H3N2). En los menores de 65 años, el exceso de mortalidad se observó en 2009 durante el mes de julio, en el cual circuló influenza A (H1N1) pdm 2009 (Tabla 1). Tres estaciones (2006, 2008 y 2010) no estuvieron asociadas a exceso de mortalidad. En el grupo de los mayores de 65 años se observó un exceso de mortalidad por neumonía e influenza con tasas de 84,1 x 100.000 y de 6,7 x 100.000 en menores de 65 años. El porcentaje de recuperación del virus y el porcentaje de ETI (máximo indicador) resultaron mayores en las estaciones en que se observó exceso de mortalidad (2007 y 2009), 
con diferencias significativas mediante el uso de los dos procedimientos de análisis estadísticos. Durante estas estaciones, la tasa de mortalidad máxima se registró casi cuando se alcanzaron tanto el máximo porcentaje de ETI como el pico de ocurrencia de virus influenza, identificado por el sistema de unidad centinela.

\section{Discusión}

La actividad estacional del virus influenza varía cada año, con algunas temporadas marcadas por grandes epidemias con alta morbilidad y mortalidad. La metodología empleada para su monitoreo difiere en los distintos países. En países de Europa como Francia, Portugal, Reino Unido de Gran Bretaña, España, Alemania, Bélgica, Países Bajos y Portugal, existen programas de monitoreo de influenza basados en la vigilancia clínica y virológica, que difieren en su organización, ya sea en el sistema de integración de los datos clínicos, virológicos como en el soporte financiero $^{17-24}$. Una variedad de algoritmos estadísticos han sido propuestos para el análisis de datos históricos. Algunos países han usado el método propuesto por Serfling ${ }^{9}$ para definir la incidencia de enfermedad tipo influenza y el total de infección respiratoria aguda. Cowling y cols. ${ }^{17}$, compararon el modelo de serie de tiempo, de regresión y de suma acumulada para datos de Hong Kong y E.U.A. y observaron que el modelo de serie de tiempo fue superior al método de suma acumulada para datos de Hong Kong, mientras que ambos modelos se comportaron igualmente bien con datos de E.U.A.

El concepto de determinación de umbrales para la vigilancia de influenza ${ }^{24-27}$ también presenta variaciones. El esquema de vigilancia europeo de influenza utiliza tanto denominadores de población como de consulta ${ }^{18}$ para reportar las presentaciones clínicas de ETI y describe la actividad como baja, moderada o alta. En E.U.A. ${ }^{26}$, el umbral deriva de la línea de base nacional a partir de las consultas de la práctica médica general y el umbral epidémico está basado en datos de mortalidad por neumonía e influenza en 122 ciudades. En Reino Unido de Gran Bretaña, se describen diferentes niveles de actividad de influenza en base a umbrales definidos ${ }^{20}$.

La estrategia de Unidades Centinelas descrita, no tiene base poblacional, por lo tanto no permite identificar incidencia y prevalencia en una población de referencia y su diseño no persigue este resultado. El efecto de la circulación viral sobre la morbilidad se mide a través de la evolución del indicador de la proporción de ETIs atendidas por médicos centinelas. En nuestro estudio se estableció la determinación de una línea de base clínica (utilizando la misma definición del sistema de E.U.A.) y, a partir de las consultas de ETI registradas por los médicos centinelas y usando como denominador las consultas por

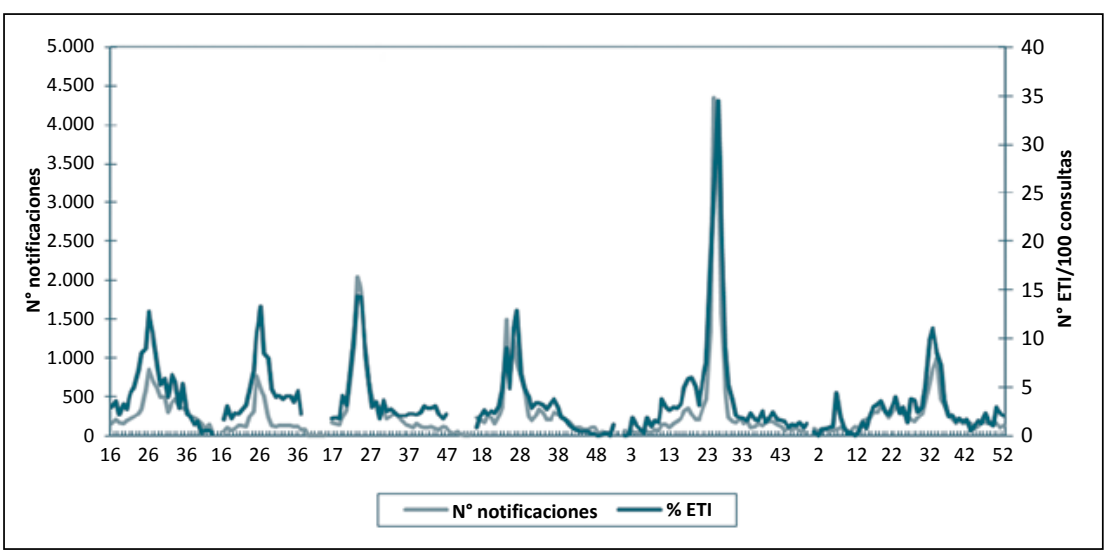

Figura 3. Concordancia entre Notificaciones Obligatorias y N ${ }^{\circ}$ ETI mediante Unidad Centinela, Santa Fe, Argentina, 2005-2010.

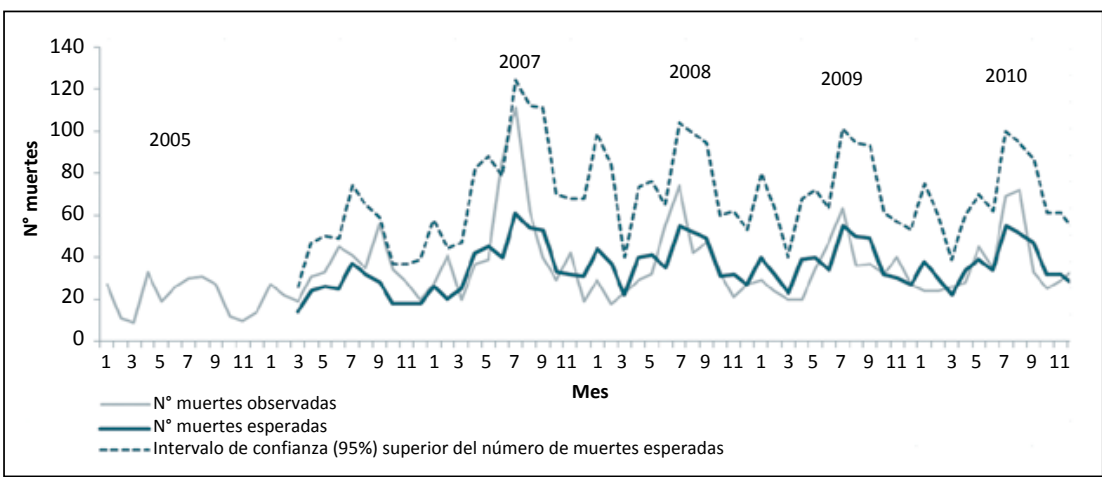

Figura 4. Mortalidad mensual por neumonía e influenza en personas mayores de 65 años. Se presenta el número de muertes observadas y el número de muertes esperadas atribuibles a neumonía e influenza, determinado por el método ARIMA. El número de muertes esperadas está representado por el límite superior del intervalo de confianza de 95\%. La Capital, Santa Fe, Argentina, 2005-2010.

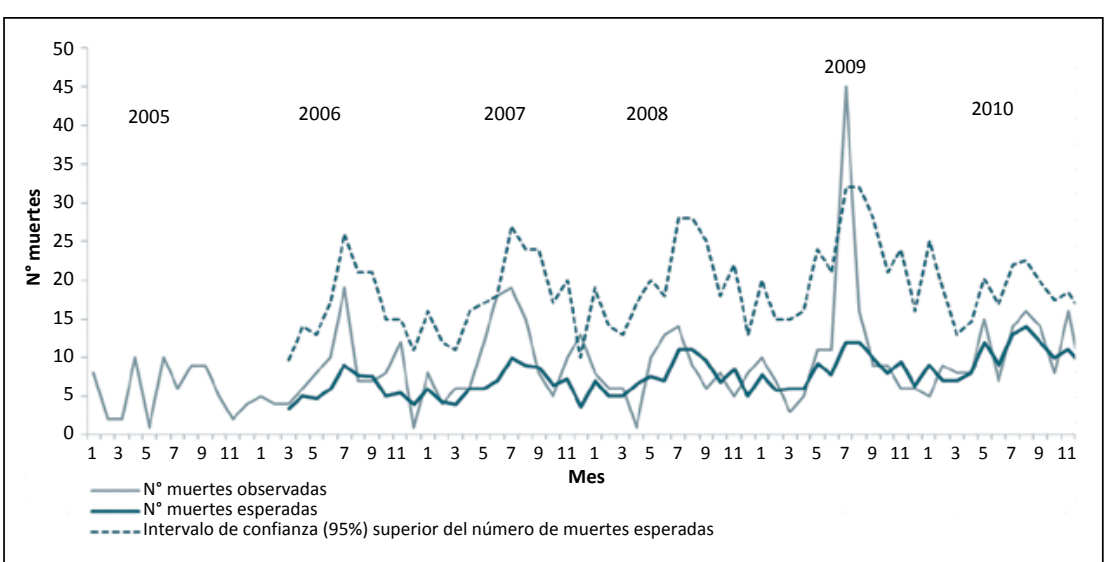

Figura 5. Mortalidad mensual por neumonía e influenza en personas menores de 65 años. Se presenta el número de muertes observadas y el número de muertes esperadas atribuibles a neumonía e influenza, determinado por el método ARIMA. El número de muertes esperadas está representado por el límite superior del intervalo de confianza de 95\%. La Capital, Santa Fe, Argentina, 2005-2010. 
todas las causas, se calculó el porcentaje de ETI. Dicho indicador epidemiológico (porcentaje de ETI) permitió caracterizar las epidemias de influenza, identificar la semana en que se registró el mayor número de personas que presentaban ETI que buscaron asistencia médica y determinar la duración de la epidemia.

El patrón estacional de circulación del virus durante el período estudiado indicó que los brotes se presentaron con intervalos aproximados de un año durante la época invernal, con picos máximos en semanas tan tempranas como la $23^{\mathrm{a}}$, así como en las semanas $26^{\mathrm{a}}$ y $27^{\mathrm{a}}$, coincidiendo con los meses de junio, julio y con una duración de 5,5 semanas (mediana). Sin embargo, durante el 2010 el máximo indicador se registró a fines de agosto (semana $33^{\mathrm{a}}$ ) coincidiendo con la circulación de virus influenza B, registrándose además una segunda ola a partir de la semana $43^{\text {a }}$ debida a virus influenza $\mathrm{A}(\mathrm{H} 3 \mathrm{~N} 2)$, correspondiendo a los meses cálidos (primavera y verano), sin detectarse un aumento de las ETI por encima de la línea de base.

En el Departamento La Capital, todos los servicios de salud pública informan semanalmente el número de casos de ETI reportada por el sistema C2. Aunque este es un muy buen indicador de la morbilidad atribuible a influenza, la tardanza y la existencia de sub-registros en la notificación de los casos dificulta la identificación precoz del brote. Sin embargo, su análisis retrospectivo permite caracterizar la magnitud de la epidemia. Teniendo en cuenta que los sistemas de notificación obligatoria suelen contar con un cierto retraso, se podría considerar que la información obtenida por unidades centinelas que debe recopilar datos con una tardanza de hasta una semana, permite obtener la información acerca de la intensidad de la circulación viral en tiempo real para la elaboración de los programas de salud y la toma de decisiones a corto plazo.

Existen variadas estrategias de vigilancia de influenza y por lo tanto la comparación con los sistemas de vigilancia de otros países es dificultosa, ya que existen diferencias en la definición de período epidémico, en la determinación de la línea de base clínica y en el tipo de numeradores y denominadores. En este contexto, la necesidad de armonización y unificación de los métodos empleados para estimar la magnitud de la morbilidad relacionada a influenza sería esencial.

Por otra parte, el uso de datos de mortalidad es una fuente valiosa para cuantificar el impacto de una epidemia de influenza ya que la gravedad relativa de una epidemia se puede estimar por el exceso de muertes por neumonía e influenza ${ }^{8-11}$. El impacto de la influenza en la mortalidad varía anualmente y ocurre como resultado de una compleja interacción entre el virus influenza y la población humana, incluyendo diferencias en virulencia y transmisibilidad de cepas y diferencias en susceptibilidad de la población general a la infección debido a exposición previa a cepas antigénicamente similares. En este estudio hemos aplicado el modelo ARIMA a los datos de mortalidad mensual por neumonía e influenza en personas mayores y menores de 65 años para estimar el exceso de mortalidad. Las temporadas 2007 y 2009, en las cuales se demostró un exceso de mortalidad, fueron acompañadas por mayor proporción de recuperación del virus influenza durante la semana pico y porcentaje de ETI, coincidiendo con otros estudios ${ }^{28}$. En 2010, a pesar de no registrarse exceso de muertes, el porcentaje de positividad resultó elevado; la razón pudo ser debido a la incorporación de una técnica más sensible (RPC-TR) respecto de la inmunofluorescencia que sólo se utilizaba hasta el 2008.

Los patrones de edad específica de muertes de influenza varían dependiendo si la estación de influenza es epidémica o pandémica. Durante las estaciones epidémicas, la proporción de muertes relacionadas a influenza es superior entre personas mayores de 65 años de edad ${ }^{29}$. Mientras que durante las estaciones pandémicas, el incremento relativo en la tasa de mortalidad es superior para personas jóvenes (menores de 65 años) que para mayores de 65 años de edad. Nuestras estimaciones de exceso de mortalidad debido a influenza fueron sustanciales, especialmente en 2009 en el grupo de edad de menores de 65 años, que se caracterizó por la presencia de influenza $\mathrm{A}(\mathrm{H} 1 \mathrm{~N} 1) \mathrm{pdm}$ $2009^{29,34-36}$, y en 2007 en mayores de 65 años, asociado a la circulación de influenza $\mathrm{A}(\mathrm{H} 3 \mathrm{~N} 2)$, así como también fue evidenciado en otros estudios ${ }^{14,31-33,37}$. Los factores que pueden explicar los patrones de mortalidad observadas es que personas mayores durante 2009 tuvieron susceptibilidad reducida debido a exposición pasada, ya fuese por infección natural o vacunación a una cepa $\mathrm{H} 1$ similar o una cepa que provee inmunidad protectora cruzada. Simonsen y cols. ${ }^{38}$, compararon la distribución de edad de muertes relacionadas a influenza en E.U.A. durante las tres pandemias. La mitad de las muertes en 1968, 1957 y en 1918 ocurrieron entre personas < 65 años de edad. Sin embargo, la proporción de muertes disminuyó durante las primeras décadas siguientes a cada pandemia.

En los años 2006, 2008 y 2010 no se produjo un exceso de mortalidad, años en los que se observó la circulación de virus influenza B y subtipo de influenza $A(H 1 N 1)$, que se conoce tienen baja severidad evidenciada por varios autores ${ }^{14,32-40}$. Esto podría deberse a que en el caso de cepas A (H1N1) han circulado desde 1918, con un intervalo entre 1957 y 1977, y se ha ido adaptando a la población humana y viceversa ${ }^{38}$. En 2010 durante la segunda ola, a pesar de la circulación de cepas de influenza A (H3N2) en una época no habitual para la región, ya que coincidió con la temporada de verano, el máximo indicador no superó la línea de base y no se produjo exceso de mortalidad alguno. Son varios los factores involucrados en la diseminación del virus influenza; no sólo la aparición de nuevos antígenos y la existencia de inmunidad en la población sino también las condiciones meteorológicas y 
los niveles de polución pueden influir en la diseminación de la enfermedad ${ }^{39}$.

Las tasas de exceso de muertes por neumonía e influenza en nuestro trabajo fueron de 6,7 y 84,1 por 100.000 habitantes para menores y mayores de 65 años, respectivamente. Como consecuencia de la variabilidad de modelos aplicados a los datos de mortalidad utilizados en otros países, la comparación de los valores resulta muy compleja; sin embargo, se encuentran dentro del mismo rango ${ }^{2,40}$.

Los datos de mortalidad por neumonía e influenza han sido ampliamente utilizados ${ }^{2,9-11,14,31}$; otros estudios han utilizado datos de mortalidad por todas las causas ${ }^{32} \mathrm{o}$ debido a causas cardíacas y respiratorias ${ }^{40}$ ya que muchas muertes son causadas por complicaciones secundarias (fallas cardíacas) y al considerar la mortalidad solamente por neumonía e influenza como causa principal de muerte, estaríamos subestimando la carga de influenza. Por este motivo, en nuestro análisis se tuvo en cuenta la causa respiratoria en cualquier orden en el certificado de defunción.

Una de las limitaciones de nuestro estudio podría ser que para la estimación del exceso de mortalidad se utilizó el dato de causa de muerte que no siempre es confirmada por métodos de laboratorio. No fueron evaluados otros factores como la actividad por el virus respiratorio sincicial y factores climáticos que pudieron haber contribuido a la mortalidad respiratoria de los grupos estudiados.

La estrategia de unidad centinela es una metodología sencilla, ágil, económica, específica y oportuna, que permite identificar la tendencia de la ocurrencia de la influenza en el tiempo. Mientras que la vigilancia clínica monitorea la diseminación de la enfermedad en la comunidad, la vigilancia virológica es esencial para la identificación temprana de nuevos virus como causa de las epidemias. La mortalidad por neumonía e influenza demostró ser un indicador preciso para determinar la magnitud de las epidemias de influenza, con la desventaja que los datos se obtienen con cierto retraso. La imple- mentación de una red informática y la consideración del ingreso al sistema de todas las causas de muerte que se detallan en el certificado de defunción, permitiría disponer de una alerta temprana que, acompañada de la vigilancia centinela, serían particularmente importantes para determinar programas de prevención y control de la influenza.

Agradecimientos: Los autores agradecen a la Dirección de Estadísticas y a la Dirección de Epidemiología de la Provincia de Santa Fe dependientes del Ministerio de Salud y Ambiente.

\section{Resumen}

Introducción: Los virus influenza son agentes patógenos de gran importancia para la salud pública. Objetivos: Describir la actividad de influenza y evaluar su impacto en la morbilidad y mortalidad durante el período 2005 - 2010 en Santa Fe, Argentina. Métodos: A partir de la vigilancia centinela se han calculado indicadores epidemiológicos y virológicos. Se analizaron datos de mortalidad en mayores y menores de 65 años, utilizando el método auto-regresivo integrado de promedios móviles y se determinó el exceso de mortalidad atribuible a influenza. Resultados: El efecto de la circulación viral sobre la morbilidad se midió a través de la proporción de pacientes con ETI. El pico de incidencia se observó entre la semana 23 y 33. Se identificó exceso de muertes en 2007 en mayores de 65 años y en 2009 en menores de 65 asociado a la circulación de influenza A(H3N2) e influenza A(H1N1)pdm 2009, respectivamente, acompañado de mayor proporción de recuperación del virus y porcentaje de ETI. Conclusión: La vigilancia centinela es sencilla, oportuna e identifica la tendencia de la ocurrencia de influenza en el tiempo. Las estimaciones demuestran que el virus ha ejercido un aumento de la mortalidad en $>65$ años en períodos epidémicos asociado al subtipo H3N2 y en $<65$ años en período pandémico con la circulación del nuevo virus.

\section{Referencias bibliográficas}

1.- Housworth J, Langmuir AD. Excess mortality from epidemic influenza, 1957-1966. Am J Epidemiol 1974; 100: 40-8.

2.- Estimates of deaths associated with seasonal influenza Unites States,1976-2007. MMWR Morb Mortal Wkly Rep 2010; 59 (33): 1057-62.

3.- Olson D R, Heffernan R, Paladini M, Konty K, Weiss D, Mostashari F. Monitoring the impact of influenza by age: emergency department fever and respiratory complaint surveillance in New York City. PLoS Med 2007; 4 (8): e247. doi:101371/journal.p,med.0040247. (accedido
01/07/2012).

4.- Cámara Larrauri A, Jiménez-J S, Méndez S L, Ontañón S M. Vigilancia de la pandemia de gripe (H1N1) 2009 España. Rev Esp Salud Pública 2010; 84: 569-88.

5.- Fleming D M, Elliot A J. Lessons from 40 years'surveillance of influenza in England and Wales. Epidemiol. Infect 2008; 136: 866-75.

6.- Yohannes K, Roche P, Hampson A, Miller M, Spencer J. Annual Report of the National Influenza Surveillance Scheme, 2003. Commun Dis Intell 2004; 28: 160-8.

7.- Protocolo genérico para la vigilancia de la influenza. 2009. Organización Panamericana de la Salud. CDC. http://new.paho.org/hq/
dmdocuments/2009/Protocolo Gen ESP.pdf.

8.- Lui K J, Kendal A. Impact of influenza epidemics on mortality in the United States from October 1972 to May 1985. Am J Public Health 1987; 77 (6): 712-6.

9.- Serfling R E. Methods for current statistical analysis of excess pneumonia-influenza deaths. Public Health Reports 1963; 78 (6): 494-506.

10.- Lee V, Yap J, Ong J, Chan K, Lin R, Chan S, et al. Influenza excess mortality from 1950-2000 in Tropical Singapore. PLoS ONE 2009; 4 (12): e8096.doi:10.1371/journal. pone.0008096. (accedido 10/07/2012)

11.- Choi K, Thacker S B. An evaluation of influenza 
mortality surveillance, 1962-1979. Time series forescasts of expected pneumonia and influenza deaths. Am J Epidemiol 1981; 113 (3): 215-26.

12.- Choi K, Thacker S B. An evaluation of influenza mortality surveillance, 1962-1979. Percentage of pneumonia and influenza deaths as an indicator of influenza activity. Am J Epidemiol 1981; 113 (3): 227-35.

13.- Allard R. Use of time-series analysis in infectious disease surveillance. Bull World Health Org 1998; 76 (4): 327-33.

14.- Kusznierz G, Imaz MS, Zerbini E, Savy V, Knez V, Sequeira M. Efecto de las epidemias de influenza sobre la mortalidad en Santa Fe, Argentina, en 1992-1999. Rev Panam Salud Pública 2002; 12 (1): 26-36.

15.- Fleming D M, Zambon M, Bartelds A I. Population estimates of persons presenting to general practitioners with influenza-like illness, 1987-96: a study of the demography of influenza-like illness in sentinel practice networks in England and Wales, and in The Netherlands. Epidemiol Infect 2000; 124: 245-53.

16.- Fleming D M, Zambon M, Bartelds A I, de Jong J C. The duration and magnitude of influenza epidemics: a study of surveillance data from sentinel general practices in England, Wales and the Netherlands. Eur J Epidemiol 1999; 15: 467-73.

17.- Cowling B J, Wong I O, Ho L M, Riley S, Leung G M. Methods for monitoring influenza surveillance data. International J Epidemiol 2006; 35: 1314-21.

18.- Manuguerra J C, Mosnier A, Paget W J; EISS (European Influenza Surveillance Schme). Monitoring of influenza in the EISS European member countries from October 2000 to April 2001. Euro Surveill 2001; 6: 127-35.

19.- Cooke M K, Crofts J P, Joseph C A, Goddard NL, Ellis J, Zambon M, et al. Influenza and other respiratory viruses surveillance in the United Kingdom: October 2003 to May 2004. CDR Supplement 2004; 1-8. http://www.hpa.org.uk/CDR/archives/2005/ flu2004_5.pdf

20.- Zhao H, Cooke M K, Joseph C A, Ellis J, Zambon M, Fleming D M, et al. Surveillance of influenza and other respiratory viruses in the United Kingdom: October 2004 to May 2005. CDR 2005 Weekly Supplement:
1-8. http://www.flu.org.cn/upfile/ attachment/2006789500556.pdf

21.- Snacken R, Lion J, Van Casteren V, Cornelis R, Yane F, Mombaerts M, et al. Five year of sentinel surveillance of acute respiratory infections (1985-1990): the benefits of an influenza early warning system. Eur J Epidemiol 1992; 8: 485-90.

22.- Bartelds AIM, Fracheboud J, van der Zee J, eds. The Dutch sentinel practice network; relevance for public health policy. Studies from the continuous morbidity registration sentinel stations of the Netherlands. Utrecht: Netherlands Institute of Primary Health Care (NIVEL), 1989: 60.

23.- Andrade H R, Figueredo M V, Oliveira M J, Paixao M T, Falcao J M. Influenza during the years 1991-1992 and 1992-1993. Results of epidemiological surveillance. Saude Numeros 1993; 8: 17-21.

24.- Fleming D M, Cohen M. Experience of European collaboration in influenza surveillance in the winter of 1993-1994. J Public Health Med 1996; 18: 133-42.

25.- Watts C, Andrews R, Druce J, Kelly H. Establishing thresholds for influenza surveillance in Victoria. Aust N Z Public Health 2003; 27: 409-12.

26.- Update: influenza activity-United States, 2001-02 season. MMWR Morb Mortal Wkly Rep 2002; 51: 276-9.

27.- Quénel P, Dab W. Influenza A and B epidemic criteria based on time-series analysis of health services surveillance data. Eur J Epidemiol 1998; 14: 275-85.

28.- Ramírez A, Mendoza A, Montoya J, Cortés K, López J, Herrera D, et al. Mortalidad asociada con las temporadas de mayor circulación de los virus de la influenza en Bogotá, Colombia, 1997-2005. Rev Pan Salud Pública 2009; 26 (5): 435-9.

29.- Rizzo C, Bella A, Viboud C, Simonsen L, Miller M, Rota M, et al. Trends for influenzarelated deaths during pandemic and epidemic seasons, Italy, 1969-2001. Emerg Infect Dis 2007; 13 (5): 694-9.

30.- Foppa I, Hossain M. Revised estimates of influenza-associated excess mortality, United States, 1995 through 2005. Emerg Themes Epidemiol 2008; 5: 26.

31.- Imaz S, Eimann M, Poyard E, Savy V. Exceso de mortalidad asociada a influenza en Argentina 1992-2002. Rev Chilena Infectol 2006; 23 (4): 297-306.

32.- Cohen C, Simonsen L, Kang J, Miller M, McAnerney J, Blumberg L, et al. Elevated influenza-related excess mortality in South African elderly individuals, 1998-2005. Clin Infect Dis 2010; 51 (12): 1362-9.

33.- Wong C, Chan K, Hedley J, Peiris M. Influenza-associated mortality in Hong Kong. Clin Infect Dis 2004; 39 : 1611-7.

34.- Muscatello D, Cretikos M, Maclntyre R. All-cause mortality during first wave of pandemic (H1N1) 2009, New South Wales, Australia, 2009. Emerg Infect Dis 2010; 16 (9): 1396-402.

35.- Gómez I, Segovia M, Jorge S, Cámara A, Suárez R, Soria F. Excesos de mortalidad en España durante la transmisión de gripe pandémica en el año 2009. Rev Esp Salud Pública 2010; 84: 589-96.

36.- Mazick A, Gergonne B, Wuillsume F, Danis K, Vantarakis A, Uphoff H, et al. Higher all-cause mortality in children during Autumm 2009 compared with the three previous years: pooled results from eight European countries. Euro Surveill 2010;15(5).pii=19480. www.eurosurveillance.org/ViewArticle. aspx?Articleld $=19480$.

37.- Centers for Disease Control and Prevention. Serum cross-reactive antibody response to a novel influenza A (H1N1) virus after vaccination with seasonal influenza vaccine. MMWR Morb Mortal Wkly Rep. 2009; 58: $521-4$

38.- Simonsen L, Clarke M, Schonberger L, Arden N, Cox N, Fukuda K. Pandemic versus epidemic influenza mortality: A pattern of changing age distribution. J Infect Dis 1998; 178: 53-60.

39.- Ravelli A C J, Kreis IA. A time series analysis of sulphurdioxide, temperature, and influenza incidence in 1976-1987. Public Health Rev 1991-92; 19: 93-101.

40.- Nunes B, Viboud C, Machado A, Ringholz C, Andrade H, Nogueira P, et al. Excess mortality associated with influenza epidemics in Portugal, 1980 to 2004. PLoS ONE 2011; 6 (6) e20661. Doi:10.1371/journal.pone.0020661 (accedido 20/07/2012). 